\title{
The ginsenoside metabolite compound $K$ inhibits growth, migration and stemness of glioblastoma cells
}

\author{
SANGHUN LEE ${ }^{1}$, MIN CHEOL KWON ${ }^{2}$, JUN-PIL JANG ${ }^{2}$, JAE KYUNG SOHNG ${ }^{1}$ and HYE JIN JUNG ${ }^{1}$ \\ ${ }^{1}$ Department of BT-Convergent Pharmaceutical Engineering, Sun Moon University, Tangjeong-myeon, Asan-si, \\ Chungnam 336-708; ${ }^{2}$ Anticancer Agent Research Center, Korea Research Institute of Bioscience \\ and Biotechnology (KRIBB), Cheongju, Chungbuk 363-883, Republic of Korea
}

Received April 14, 2017; Accepted June 14, 2017

DOI: 10.3892/ijo.2017.4054

\begin{abstract}
Glioblastoma (GBM) is the most aggressive and malignant form of primary brain cancer. Despite recent advances in cancer treatment, it remains a substantially incurable disease. Accordingly, more effective GBM therapeutic options are urgently required. In the present study, we investigated the anticancer effect of a ginsenoside metabolite, compound K (CK), against GBM cells. CK significantly inhibited not only growth, but also metastatic ability of U87MG and U373MG cells. CK arrested cell cycle progression at the G0/G1 phase with a decrease in the expression levels of cyclin D1 and cyclin D3 in both cell types. CK also induced apoptosis in GBM cells through nuclear condensation, an increase in ROS generation, mitochondrial membrane potential depolarization, and activation of caspase-3, caspase-9 and poly(ADP-ribose) polymerase (PARP). Furthermore, CK inhibited phosphatidylinositol 3-kinase (PI3K)/protein kinase $\mathrm{B}(\mathrm{Akt}) / \mathrm{mammalian}$ target of rapamycin (mTOR) signaling pathway, contributing to the antiproliferative and apoptotic effects. Moreover, CK suppressed the self-renewal capacity as well as the invasiveness of U87MG and U373MG GBM stem-like cells (GSCs) by inducing a reduction in the expression of GSC markers, such as CD133, Nanog, Oct4 and Sox 2 . Taken together, our findings suggest that CK may potentially be useful for GBM treatment.
\end{abstract}

\section{Introduction}

Glioblastoma (GBM) is the most common and aggressive primary brain tumor, accounting for more than $50 \%$ of all brain tumors (1). Even with the current standard treatment composed of maximal surgical removal, radiotherapy and chemotherapy with temozolomide (TMZ), the median survival

Correspondence to: Professor Hye Jin Jung, Department of BTConvergent Pharmaceutical Engineering, Sun Moon University, 70 Sunmoon-ro 221, Tangjeong-myeon, Asan-si, Chungnam 336-708, Republic of Korea

E-mail: poka96@sunmoon.ac.kr

Key words: anticancer effect, glioblastoma, glioblastoma stem-like cells, ginsenoside, compound $\mathrm{K}$ period of GBM patients is approximately 14 months $(2,3)$. Multimodal treatment with radiotherapy and TMZ increases the survival rate compared with radiotherapy alone. Despite the current treatment regime, the prognosis for GBM patients is still very poor because of tumor recurrence. There are several causes of recurrence including unclear tumor margins following surgical removal, a fast growth rate and resistance to chemotherapy and radiotherapy (4). Particularly for the GBM stem cell (GSC) subpopulation, possessing a high carcinogenic potential and self-renewing ability has been identified and is believed to contribute to GBM propagation and resistance to conventional therapies (5). Thus, the development of new anticancer agents targeting both cancer cells and cancer stem cells in GBM could be a promising therapeutic strategy to more effectively eradicate malignant tumors.

Ginseng has been consumed as traditional medicine for thousands of years in Asia (6). There are extensive reports regarding ginseng's many pharmacological effects on the endocrine, immune, cardiovascular and the central nervous systems (7). There are also many reports that ginseng has antiaging and antioxidant properties (8). The various pharmacological and biological effects of ginseng are mainly mediated by compounds from the saponin group, called ginsenosides (9). Accumulating evidence has revealed that the major functional components of ginsenoside have antiinflammatory, antidiabetic and antitumor effects $(10,11)$. While $>40$ ginsenosides have been identified, their chemical structures have difficulties with absorption when orally administered (12). More than $80 \%$ of the known ginsenosides can be classified into two structural groups: the protopanaxadiol (PPD)-type (e.g., Rb1, Rb2, Rb3, Rc, Rd, Rg3, $\mathrm{Rh} 2$ and Rs1) that have sugar moieties attached to the $\beta-\mathrm{OH}$ at C3 and/or C20 and the protopanaxatriol (PPT)-type (e.g., Re, Rf, Rg1, Rg2 and Rh1) that have sugar moieties attached to the $\alpha-\mathrm{OH}$ at $\mathrm{C} 6$ and/or the $\beta-\mathrm{OH}$ at $\mathrm{C} 20$. Compound $\mathrm{K}$ [20-O- $\beta$-d-glucopyranosyl-20(S)-protopanaxadiol, $\mathrm{CK}]$ is the major metabolite of ginsenosides $\mathrm{Rb} 1, \mathrm{Rb} 2, \mathrm{Rc}$ and $\mathrm{Rd}$ that are synthesized by intestinal bacteria after oral administration of ginseng (Fig. 1A) (13). CK is absorbed in the gastrointestinal tract before being slowly metabolized $(14,15)$. Several studies have indicated that $\mathrm{CK}$ possesses anticancer activity against a variety of tumor cell types by inhibiting cell proliferation and inducing apoptosis $(16,17)$. CK also has antimetastatic 
potential in various tumor cells $(18,19)$. Despite the long-term study of the CK anticancer efficacy, there has been no research on GBM cells, including GSCs.

In the present study, we investigated the anticancer effect of CK on GBM and the underlying mechanisms involved. Our results showed that $\mathrm{CK}$ inhibited the growth and metastatic ability of GBM cells, inducing cell cycle arrest and apoptosis. Furthermore, we identified a therapeutic effect of CK against the cancer stem cell-like phenotypes of GBM cells, GSCs. Our findings provide evidence that $\mathrm{CK}$ may be a potential therapeutic drug against GBM.

\section{Materials and methods}

Materials. Compound K was obtained from Ilhwa Co., Ltd., (Guri, Korea) and dissolved in dimethyl sulfoxide (DMSO) at a concentration of $50 \mathrm{mM}$ as a stock solution. Gelatin and Matrigel were purchased from Sigma-Aldrich (St. Louis, MO, USA) and BD Biosciences (San Jose, CA, USA), respectively. Anti-MMP-2 (64 kDa), anti-MMP-9 (84 kDa), anti-cyclin D1 (36 kDa), anti-cyclin D3 (31 kDa), anti-PARP (89, $116 \mathrm{kDa})$, anti-cleaved caspase-3 (Asp175, 17, $19 \mathrm{kDa})$, anti-cleaved caspase-9 (Asp330, $37 \mathrm{kDa}$ ), anti-phospho-PI3K [p85 (Tyr458)/p55 (Tyr199), 60 and $85 \mathrm{kDa}$, anti-PI3K (p85, $85 \mathrm{kDa}$ ), anti-phospho-Akt (Ser473, $60 \mathrm{kDa}$ ), anti-Akt (60 kDa), anti-phospho-mTOR (Ser2448, $289 \mathrm{kDa})$, anti-mTOR (289 kDa), anti-Nanog (42 kDa), anti-Sox2 (35 kDa), anti-Oct4 (45 kDa) and anti- $\beta$-actin (45 kDa) antibodies were obtained from Cell Signaling Technology (Danvers, MA, USA). Anti-CD133 (133 kDa) antibody was obtained from Miltenyi Biotec GmbH (Bergisch Gladbach, Germany).

Cell culture. Human glioblastoma U87MG and U373MG cell lines were obtained from the Korean Cell Line Bank (KCLB; Seoul, Korea). The cells were cultured in minimum essential medium (MEM; Gibco, Grand Island, NY, USA) supplemented with $10 \%$ fetal bovine serum (FBS; Gibco) and $1 \%$ penicillin-streptomycin-amphotericin B (Lonza, Walkersville, MD, USA) and then maintained at $37^{\circ} \mathrm{C}$ in a humidified $5 \%$ $\mathrm{CO}_{2}$ incubator.

Cell growth assay. Cell growth was examined using the 3-(4,5-dimethylthiazol-2-yl)-2,5-diphenyltetrazolium bromide (MTT) colorimetric assay. Dissociated GBM cells were seeded in a 96-well culture plate at a density of $3 \times 10^{3}$ cells/well. After a 24-h incubation, CK (6.25-100 $\mu \mathrm{M})$ was added to each well and incubation was resumed. After $72 \mathrm{~h}, 50 \mu \mathrm{l}$ of MTT solution ( $2 \mathrm{mg} / \mathrm{ml}$; Sigma-Aldrich) was added to each well followed by incubation for $3 \mathrm{~h}$ at $37^{\circ} \mathrm{C}$. To dissolve formazan crystals, the culture medium was removed and an equal volume of DMSO was added to each well. The absorbance of each well was determined at a wavelength of $540 \mathrm{~nm}$ using a microplate reader (Thermo Fisher Scientific, Vantaa, Finland).

Colony formation assay. To evaluate the colony forming inhibitory effect of CK, GBM cells were seeded in a 6-well cell culture pate at a density of 500 cells/well. After 24-h incubation, the cells were treated with CK $(10,25$ and $50 \mu \mathrm{M})$ for 8 days. Following this, the colonies were fixed with $4 \%$ formaldehyde and stained with $0.5 \%$ crystal violet solution.
Wound healing assay. GBM cells were seeded in a 24-well cell culture plate at a density of $7 \times 10^{4}$ cells/well and grown to $90 \%$ confluence. The confluent monolayer cells were scratched using a pipette tip and each well was washed with phosphate-buffered saline (PBS) to remove non-adherent cells. The cells were treated with CK $(10,25$ and $50 \mu \mathrm{M})$ and then incubated for up to $48 \mathrm{~h}$. The perimeter of the central cell-free zone was confirmed under an optical microscope (Olympus, Center Valley, PA, USA).

Invasion assay. Cell invasion was assayed using Transwell chamber inserts with a pore size of $8.0 \mu \mathrm{m}$ (Corning Costar, Acton, MA, USA). The lower side of the polycarbonate filter was coated with $10 \mu \mathrm{l}$ of gelatin $(1 \mathrm{mg} / \mathrm{ml})$ and the upper side was coated with $10 \mu \mathrm{l}$ of Matrigel $(3 \mathrm{mg} / \mathrm{ml})$. GBM cells $\left(1 \times 10^{5}\right)$ were seeded in the upper chamber of the filter and CK $(10,25$ and $50 \mu \mathrm{M})$ was added to the lower chamber filled with medium, and the chamber was incubated at $37^{\circ} \mathrm{C}$. After $24 \mathrm{~h}$ (for cancer cells) or $48 \mathrm{~h}$ (for cancer stem-like cells), the cells were fixed with methanol and stained with hematoxylin/eosin. The total number of cells that invaded the lower chamber of the filter was counted using an optical microscope (Olympus).

Cell cycle analysis. GBM cells were seeded in a $60-\mathrm{mm}$ culture dish at a density of $5 \times 10^{5}$ cells/dish and incubated for $24 \mathrm{~h}$. Next the cells were treated with CK $(50 \mu \mathrm{M})$ for $24 \mathrm{~h}$. Following treatment, the cells were harvested, washed with PBS, and fixed in ice-cold $70 \%$ ethanol at $-20^{\circ} \mathrm{C}$ for $>3 \mathrm{~h}$. The cells were subsequently centrifuged and incubated with a propidium iodide (PI) working solution $(10 \mu \mathrm{g} / \mathrm{ml} \mathrm{PI} \mathrm{and} 100 \mu \mathrm{g} / \mathrm{ml}$ RNase A; Sigma-Aldrich) for $30 \mathrm{~min}$ at room temperature in the dark. The cell cycle distribution was analyzed using a FACScan flow cytometer (BD Biosciences, Franklin Lakes, NJ, USA).

Apoptosis analysis. GBM cells at a density of $5 \times 10^{5}$ cells/dish were treated with CK (50 and $75 \mu \mathrm{M})$ and incubated for $24 \mathrm{~h}$. The cells were harvested, washed with PBS, and stained with Annexin V-FITC and PI according to the manufacturer's instructions for the ApopNexin Annexin V FITC Apoptosis kit (Merck Millipore, Darmstadt, Germany). The stained cells were analyzed by flow cytometry (BD Biosciences).

DAPI fluorescent staining. GBM cells were seeded in a 24 -well culture plate at a density of $5 \times 10^{4}$ cells/well. After treatment with $\mathrm{CK}(25,50$ and $75 \mu \mathrm{M})$ for $24 \mathrm{~h}$, the cells were washed with PBS, fixed in $1 \%$ formaldehyde solution for $10 \mathrm{~min}$, and then stained with 4',6-diamidino-2-phenylindole (DAPI, $5 \mu \mathrm{g} / \mathrm{ml}$; Sigma-Aldrich) for $10 \mathrm{~min}$ at room temperature. The nuclear morphology of the cells was determined by fluorescence microscopy (Optinity KI-2000F; Korea Lab Tech, Seongmam, Korea).

Intracellular reactive oxygen species (ROS) measurement. Intracellular reactive oxygen species (ROS) levels were measured using a ROS-sensitive fluorescence indicator, 2',7'-dichlorofluorescein diacetate (DCFH-DA; Sigma-Aldrich). GBM cells were seeded in a 24 -well cell culture plate at a density of $5 \times 10^{4}$ cells/well and treated with CK $(25,50$ and $75 \mu \mathrm{M})$ for $24 \mathrm{~h}$. The cells were incubated 
A
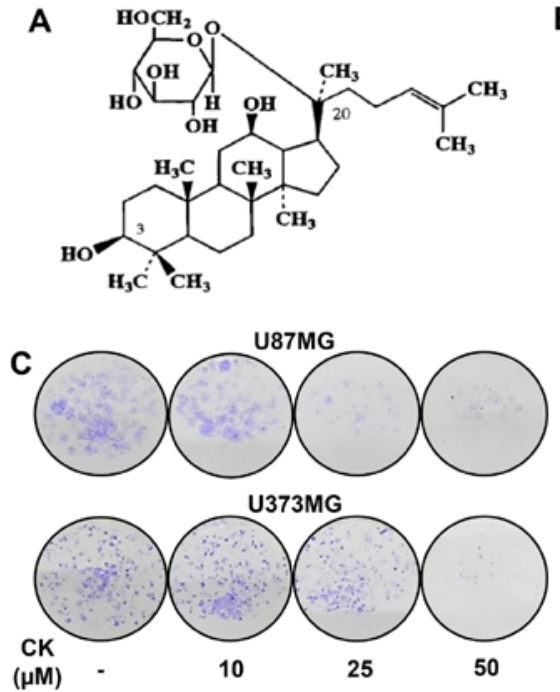
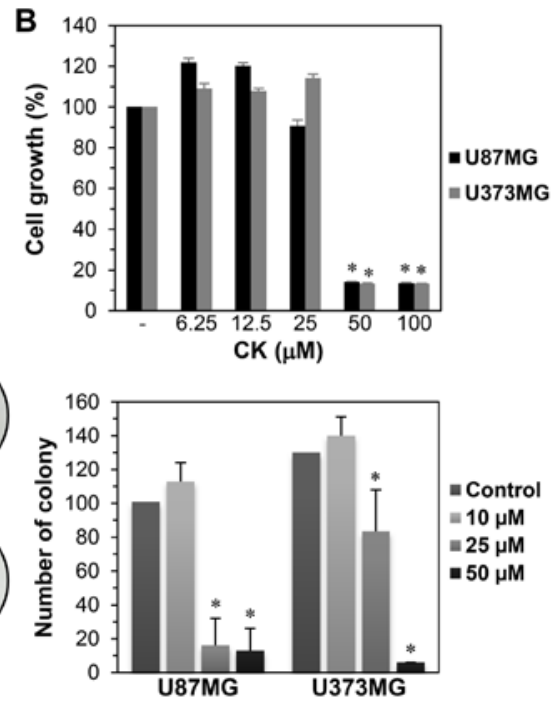

Figure 1. The growth inhibitory effect of CK on GBM cells. (A) Chemical structure of CK. (B) The effect of CK on the growth of U87MG and U373MG cells The cells were treated with increasing concentrations of CK $(0,6.25,12.5,25,50$ and $100 \mu \mathrm{M})$ for $72 \mathrm{~h}$ and cell growth was measured by MTT assay. (C) The effect of CK on the colony forming ability of U87MG and U373MG cells. The cells were incubated in the absence or presence of CK (10, 25 and $50 \mu \mathrm{M})$ for 8 days. The cell colonies were detected by crystal violet staining. ${ }^{*} \mathrm{P}<0.05$ vs. the control.

with $10 \mu \mathrm{M}$ of DCFH-DA for 30 min and then washed with PBS. The fluorescent images were obtained using an Optinity KI-2000F fluorescence microscope (Korea Lab Tech).

Mitochondrial membrane potential (MMP) determination. The mitochondrial membrane potential (MMP) was detected using the fluorescent, lipophilic dye, JC-1 (5,5',6,6'-tetrachloro-1,1',3,3'-tetraethylbenzimidazol-carbocyanine iodide; Sigma-Aldrich). At hyperpolarized membrane potentials, this dye forms a red fluorescent J-aggregate, whereas at depolarized membrane potentials, this dye remains in its green fluorescent monomeric form. GBM cells were seeded in a 24-well cell culture plate at a density of $5 \times 10^{4}$ cells/well. After treatment with $\mathrm{CK}(25,50$ and $75 \mu \mathrm{M})$ for $24 \mathrm{~h}$, the cells were incubated with $10 \mu \mathrm{g} / \mathrm{ml}$ of JC-1 for $20 \mathrm{~min}$ and washed with PBS. The images were obtained using an Optinity KI-2000F fluorescence microscope.

Western blot analysis. Cell lysates were separated by $10 \%$ SDS-PAGE and the separated proteins were transferred to polyvinylidene difluoride membranes (Millipore, Billerica, MA, USA) using standard electroblotting procedures. The blots were blocked and immunolabeled with primary antibodies against MMP-2, MMP-9, cyclin D1, cyclin D3, PARP, cleaved caspase-3, cleaved caspase-9, phospho-PI3K, PI3K, phospho-Akt, Akt, phospho-mTOR, mTOR, CD133, Nanog, Sox 2 , Oct 4 and $\beta$-actin overnight at $4^{\circ} \mathrm{C}$. Immunolabeling was detected with an enhanced chemiluminescence (ECL) kit (Bio-Rad Laboratories, Hercules, CA, USA), according to the manufacturer's instructions.

GSC culture. To propagate GSCs, U87MG and U373MG cells grown in the serum-based media were cultured in Dulbecco's modified Eagle's medium/nutrient mixture F-12 (DMEM/F12; Gibco) containing 1X B-27 serum-free supplement (Gibco), $5 \mu \mathrm{g} / \mathrm{ml}$ heparin (Sigma-Aldrich), $2 \mathrm{mM}$ l-glutamine (Gibco), $20 \mathrm{ng} / \mathrm{ml}$ epidermal growth factor (EGF; Gibco), $20 \mathrm{ng} / \mathrm{ml}$ basic fibroblast growth factor (bFGF; KOMA Biotech, Seoul, Korea) and $1 \%$ penicillin/streptomycin (Gibco). Neurospheres grown in the serum-free media were subcultured every 7 days by dissociating with Accutase (Millipore, Temecula, CA, USA) and maintained at $37^{\circ} \mathrm{C}$ in a humidified $5 \% \mathrm{CO}_{2}$ incubator.

GSC growth assay. GSC growth was evaluated using the WST-1 colorimetric assay, a water-soluble tetrazolium salt method. Dissociated neurosphere cells were seeded in a 96-well cell culture plate at a density of $3 \times 10^{3}$ cells/well using the serum-free media with EGF and bFGF. After 7 days of CK treatment (6.25-100 $\mu \mathrm{M}), 10 \mu \mathrm{l}$ of WST-1 reagent solution (DoGen, Seoul, Korea) was added to each well and the cells were incubated for an additional $3 \mathrm{~h}$ at $37^{\circ} \mathrm{C}$. The absorbance was measured at a wavelength of $450 \mathrm{~nm}$ using a microplate reader (Thermo Fisher Scientific).

Neurosphere formation assay. Dissociated neurosphere cells were seeded in a 96-well cell culture plate at a density of 200 cells/well using the serum-free media with EGF and bFGF. After 9-12 days of CK treatment (10, 25 and $50 \mu \mathrm{M})$, the number of formed neurospheres in each well was counted under a microscope.

Statistical analysis. The results are expressed as the mean \pm standard error (SE). The Student's t-test was used to determine statistical significance between the control and test groups. A $\mathrm{P}<0.05$ was considered statistically significant.

\section{Results}

Compound $K$ suppresses the growth of glioblastoma cells. To investigate the effect of CK on GBM cell growth, U87MG and U373MG cells were treated at various concentrations $(0-100 \mu \mathrm{M})$ of $\mathrm{CK}$ for $72 \mathrm{~h}$. Cell growth was then assessed using the MTT assay. As shown in Fig. 1B, a significant decrease in the growth of both cells was observed for $50 \mu \mathrm{M} \mathrm{CK}$. The 
A

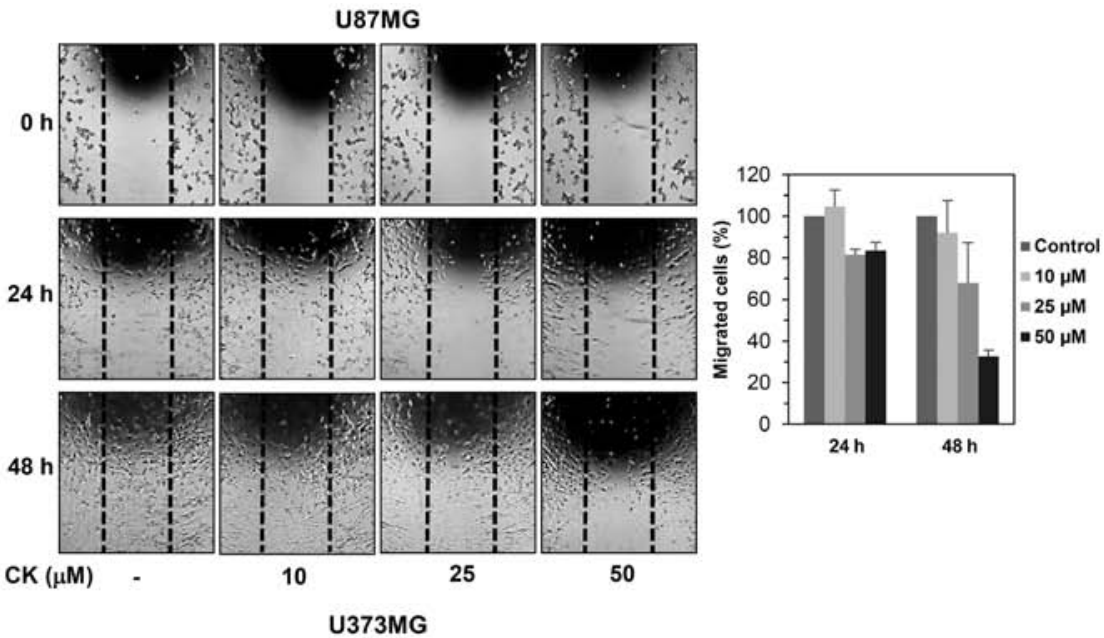

B
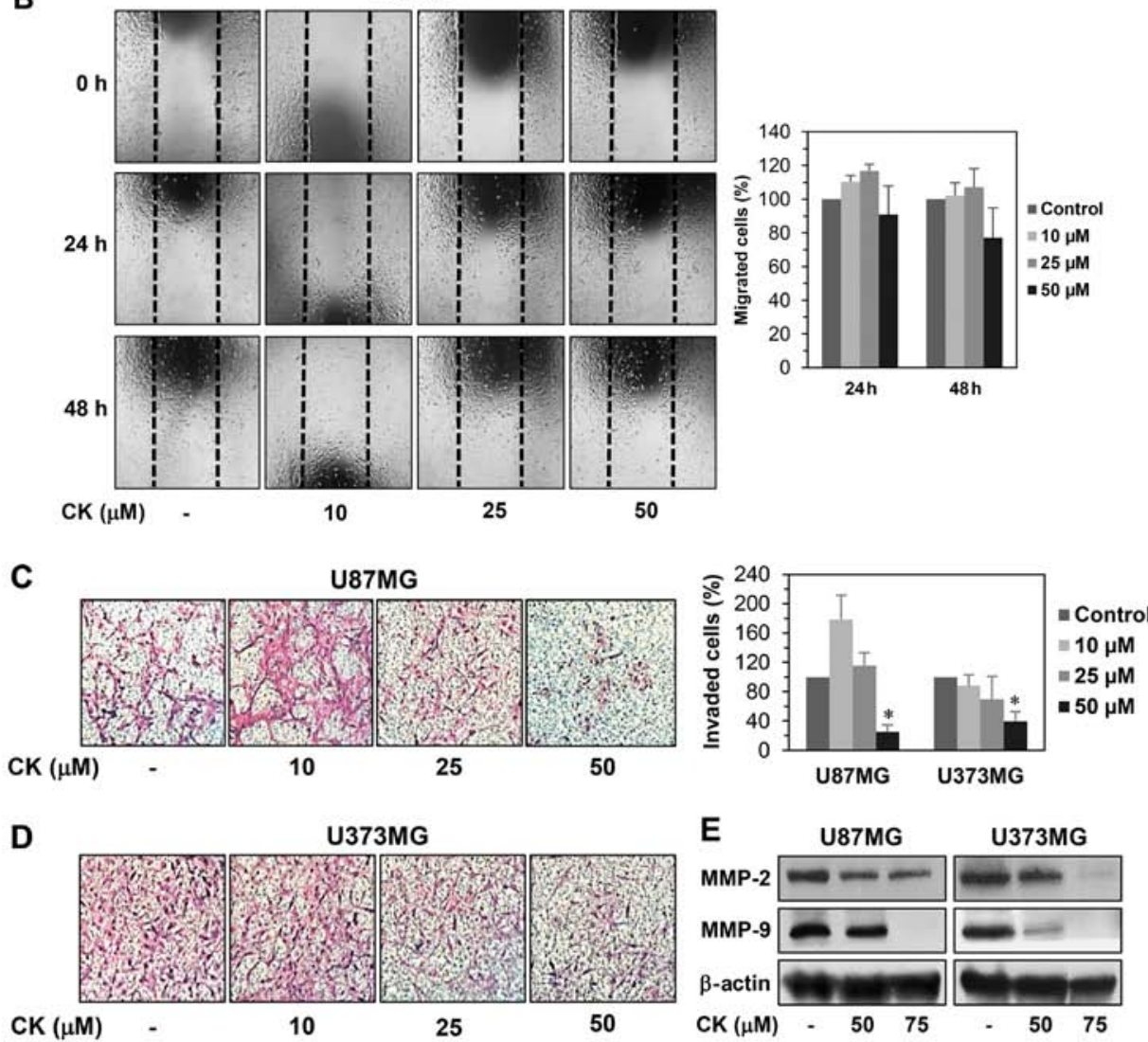

Figure 2. The effect of CK on the metastatic ability of GBM cells. (A and B) The effect of CK on the migration of U87MG and U373MG cells. The migratory potential of GBM cells was analyzed using wound healing assay. The cells were incubated in the absence or presence of CK (10,25 and $50 \mu \mathrm{M})$ for $48 \mathrm{~h}$. The cells migrated into the gap were counted under an optical microscope. Dotted black lines indicate the edge of the gap at $0 \mathrm{~h}$. (C and D) The effect of CK on the invasion of U87MG and U373MG cells. The invasiveness of GBM cells was analyzed using Matrigel-coated polycarbonate filters. The cells were incubated in the absence or presence of $\mathrm{CK}(10,25$ and $50 \mu \mathrm{M})$ for $24 \mathrm{~h}$. The cells penetrating the filters were stained and counted under an optical microscope. ${ }^{*} \mathrm{P}<0.05 \mathrm{vs}$. the control. (E) The effect of CK on the expression of MMP-2 and -9 in U87MG and U373MG cells. The cells were treated with CK (50 and $75 \mu \mathrm{M})$ for $24 \mathrm{~h}$ and the protein levels were detected by western blot analysis using specific antibodies. The levels of $\beta$-actin were used as an internal control.

growth inhibitory effect of CK against GBM cells was further assessed using a colony formation assay. U87MG and U373MG cells were treated with $\mathrm{CK}$ at concentrations of $0-50 \mu \mathrm{M}$ for 8 days. As shown in Fig. 1C, colony formation for both cell types was remarkably suppressed by treatment with 25 and $50 \mu \mathrm{M} \mathrm{CK}$, indicating that $\mathrm{CK}$ inhibited the proliferation of GBM cells.

Compound $K$ inhibits the migration and invasion of glioblastoma cells. Cell motility is an important factor for cancer metastasis (20). We therefore examined whether CK could inhibit the migration and invasion of GBM cells. A monolayer wound healing assay was performed to evaluate the effect of CK on the migration of U87MG and U373MG cells. CK at a concentration of $50 \mu \mathrm{M}$ decreased the migration of both cell types at 24 and $48 \mathrm{~h}$ after treatment when compared with the control condition (Fig. 2A and B). For the Transwell invasion assay, U87MG and U373MG cells were treated with $\mathrm{CK}$ at the indicated concentrations for $24 \mathrm{~h}$, reducing the invasiveness of both cell types in a dose-dependent manner (Fig. 2C and D). 


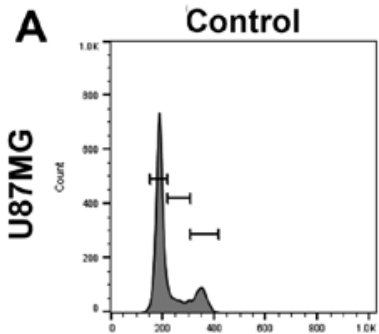

R2.4.

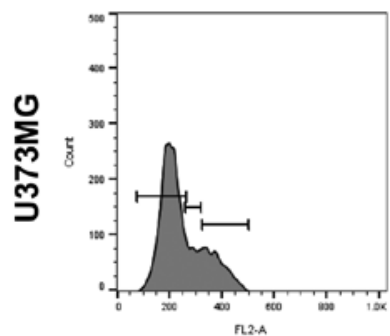

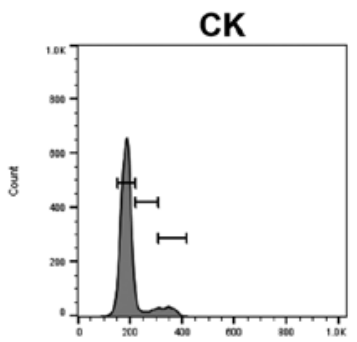

riva

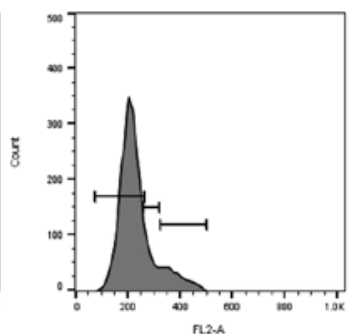

B

\begin{tabular}{lcccc}
\hline & & \multicolumn{3}{c}{ Cell cycle phase } \\
\cline { 3 - 5 } & $\begin{array}{l}\text { Concentration } \\
\text { of CK }\end{array}$ & $\begin{array}{c}\text { G0/G1 } \\
(\%)\end{array}$ & $\begin{array}{c}\text { S } \\
(\%)\end{array}$ & $\begin{array}{r}\text { G2/M } \\
(\%)\end{array}$ \\
\hline \multirow{2}{*}{ U87MG } & $\begin{array}{c}\text { Control } \\
\text { U373MG }\end{array}$ & 68.6 & 13.7 & 15.6 \\
& $50 \mu \mathrm{M}$ & 80.7 & 7.14 & 7.58 \\
\hline \multirow{2}{*}{$\begin{array}{c}\text { Control } \\
50 \mu M\end{array}$} & 66.0 & 12.9 & 21.4 \\
& & 77.3 & 11.2 & 12.3 \\
\hline
\end{tabular}

C

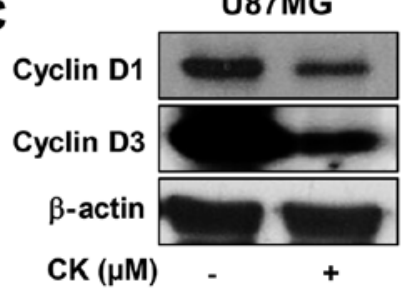

U373MG

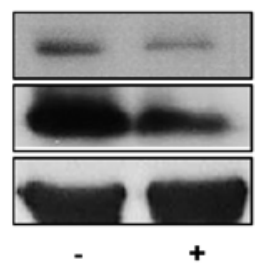

Figure 3. The effect of CK on the cell cycle of GBM cells. (A and B) The cell cycle distribution of U87MG and U373MG cells was evaluated by flow cytometry after the treatment of CK $(50 \mu \mathrm{M})$ for $24 \mathrm{~h}$. (C) The expression levels of cyclin D1 and cyclin D3 in U87MG and U373MG cells were measured by western blot analysis after the treatment of $\mathrm{CK}(50 \mu \mathrm{M})$ for $24 \mathrm{~h}$.

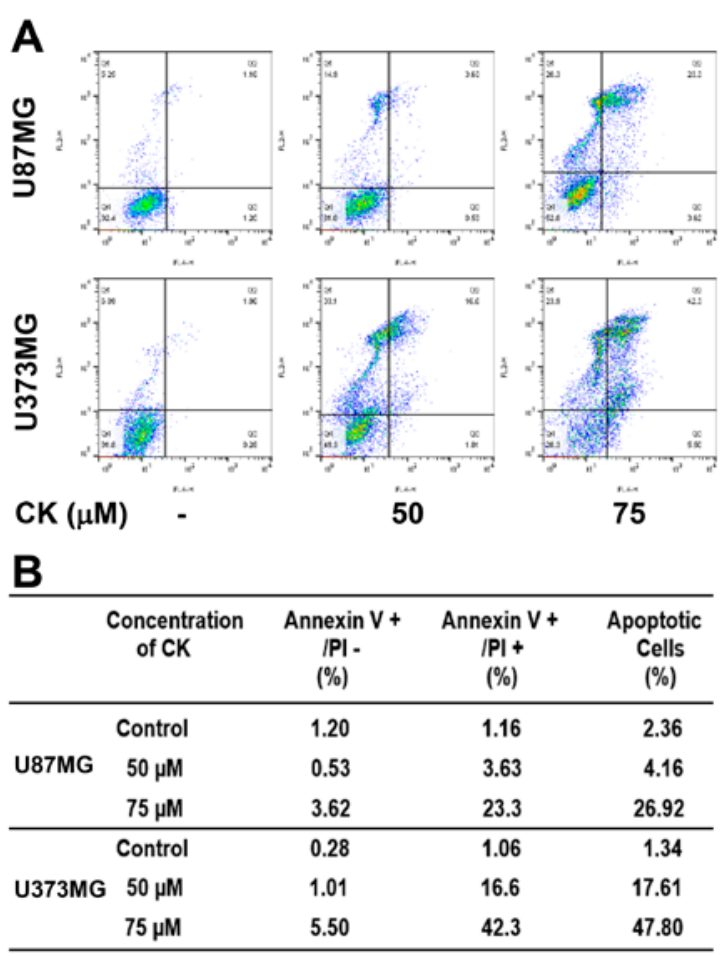

Figure 4. The effect of CK on the apoptotic cell death of GBM cells. (A and B) U87MG and U373MG cells were treated with CK (50 and $75 \mu \mathrm{M}$ ) for $24 \mathrm{~h}$. Apoptotic cells were determined by flow cytometric analysis following Annexin V-FITC and propidium iodide (PI) dual labeling.

Notably, the inhibitory effect of CK on GBM cell invasion was very potent at $50 \mu \mathrm{M}$.

A characteristic of metastatic cancer cells is the capacity to degrade extracellular matrix (ECM) through the upregulation of matrix metalloproteinases (MMPs) (21). In particular, MMP-2 and MMP-9 have been shown to play a critical role in cancer metastasis (22). To define the mechanism by which CK reduces GBM cell migration and invasion, the protein expression levels of MMP-2 and MMP-9 in U87MG and U373MG cells were investigated. As shown in Fig. 2E, CK effectively suppressed the expression of MMP-2 and MMP-9, suggesting that CK may inhibit the migration and invasion of GBM cells by decreasing MMP-2 and MMP-9 expression.

Compound $K$ induces $G 0 / G 1$ phase arrest in glioblastoma cells. To determine whether the antiproliferative effect of $\mathrm{CK}$ on GBM cells was caused by cell cycle arrest, the effect of CK on the cellular cell cycle distribution was quantified using flow cytometric analysis. U87MG and U373MG cells were treated with $50 \mu \mathrm{M}$ of $\mathrm{CK}$ for $24 \mathrm{~h}$. As shown in Fig. 3A and B, CK induced G0/G1 phase arrest (an increase in the proportion of arrested cells from 68.6 to $80.7 \%$ for U87MG cells and from 66.0 to $77.3 \%$ for U373MG cells) along with a decrease of $\mathrm{S}$ and $\mathrm{G} 2 / \mathrm{M}$ phases when compared with the control cells.

The D-type cyclins (cyclins D1, D2 and D3) are important regulators for the transition from $\mathrm{G} 0 / \mathrm{G} 1$ phase to $\mathrm{S}$ phase of the cell cycle $(23,24)$. Therefore, the effect of CK on the expression of cell cycle regulators was assessed. As shown in Fig. 3C, $50 \mu \mathrm{M}$ of CK led to a significant decrease in the protein levels of cyclin D1 and D3 in both U87MG and U373MG cells. This demonstrates that $\mathrm{CK}$ blocked cell cycle progression at the G0/G1 phase, thereby inhibiting GBM cell proliferation.

Compound $K$ induces apoptosis in glioblastoma cells. To further elucidate the anticancer effect of CK in GBM cells, cellular apoptosis was quantitatively measured using flow cytometric analysis following Annexin V-FITC and PI dual labeling. Annexin V is a marker of early apoptosis and PI is a marker of late apoptosis and necrosis $(25,26)$. When U87MG and U373MG cells were treated with $\mathrm{CK}$ at either 50 or $75 \mu \mathrm{M}$ for $24 \mathrm{~h}$, the total amount of early and late apoptotic cells were markedly increased in a dose-dependent manner after CK treatment in comparison with controls (from 2.36 to $26.92 \%$ for U87MG cells and from 1.34 to $47.8 \%$ for U373MG cells; Fig. 4). This indicates that CK induced apoptotic cell death in GBM cells. 


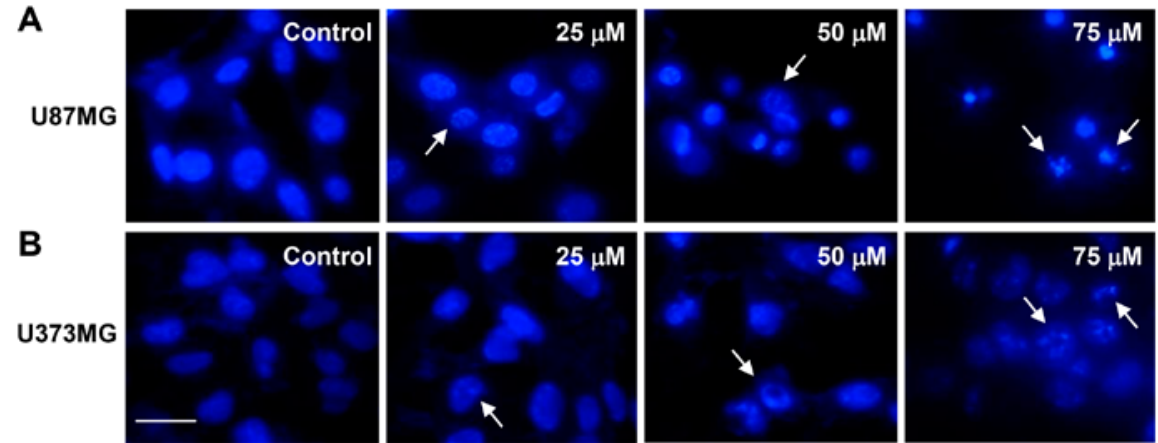

Figure 5. The effect of CK on the nuclear apoptosis of GBM cells. (A) U87MG and (B) U373MG cells were incubated in the absence or presence of CK (25, 50 and $75 \mu \mathrm{M}$ ) for $24 \mathrm{~h}$. The changes of nuclear morphology were monitored by DAPI staining. Scale bar, $50 \mu \mathrm{m}$.

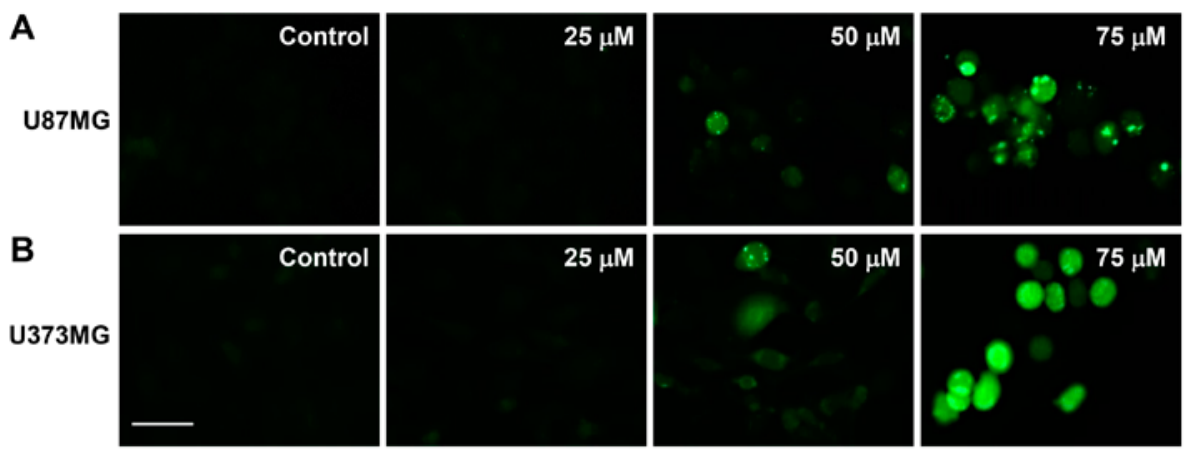

Figure 6. The effect of CK on the intracellular ROS generation in GBM cells. (A) U87MG and (B) U373MG cells were incubated in the absence or presence of CK $(25,50$ and $75 \mu \mathrm{M})$ for $24 \mathrm{~h}$. ROS levels were detected with DCFH-DA using a fluorescence microscope. Scale bar, $50 \mu \mathrm{m}$.

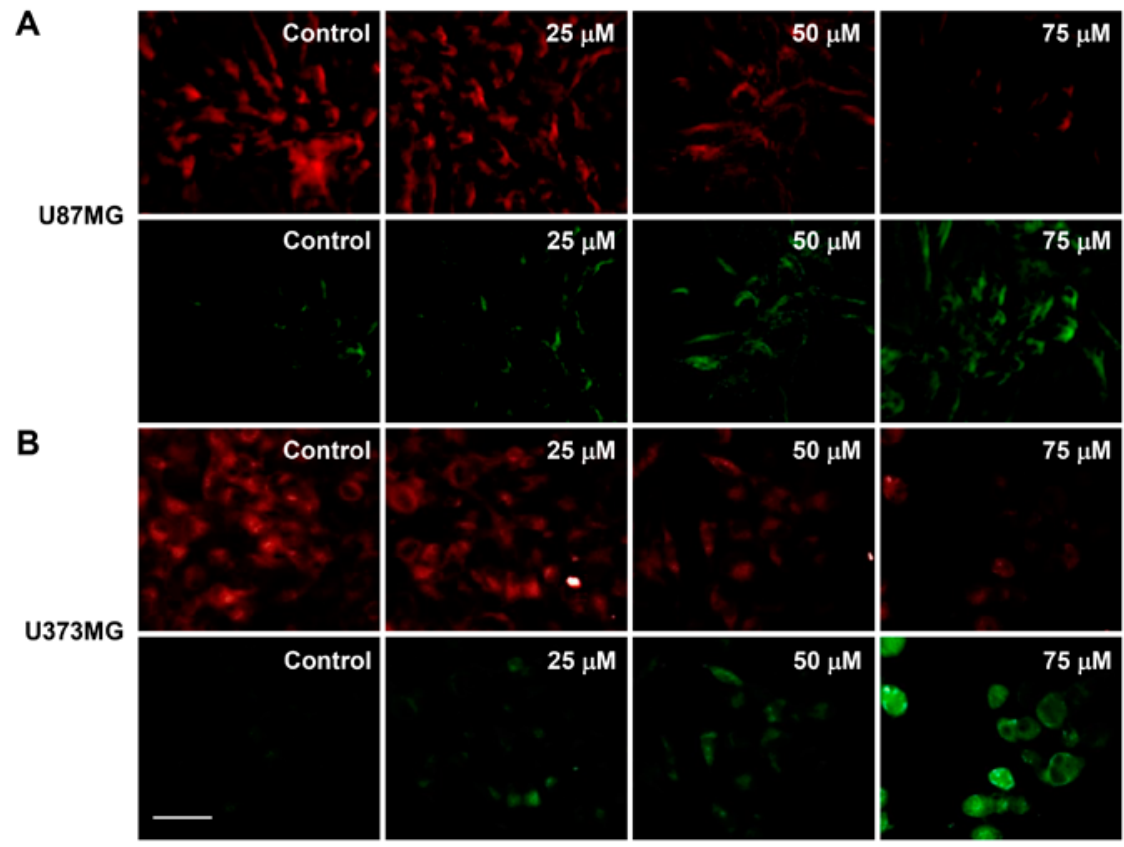

Figure 7. The effect of CK on the mitochondrial membrane potential in GBM cells. (A) U87MG and (B) U373MG cells were treated with CK (25, 50 and $75 \mu \mathrm{M}$ ) for $24 \mathrm{~h}$ and stained with JC-1. Fluorescence images were obtained with a fluorescence microscope. Scale bar, $50 \mu \mathrm{m}$.

Next, we investigated whether CK causes nuclear apoptotic changes in GBM cells. DAPI staining revealed that CK induced the nuclear condensation and fragmentation of U87MG and U373MG cells in a dose-dependent manner (as indicated by the arrows in Fig. 5).
The elevated formation of intracellular ROS plays an important role in mediating apoptotic processes (27). Therefore, to determine whether ROS are involved in the regulation of apoptosis induced by CK, the intracellular generation of ROS in GBM cells was observed using the fluorescent DCFH-DA 


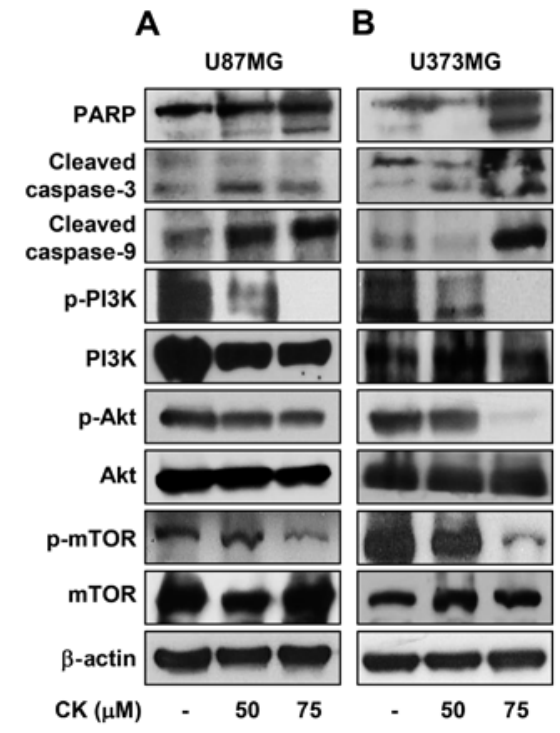

Figure 8. The effect of $\mathrm{CK}$ on the expression of apoptosis-related proteins in GBM cells. (A) U87MG and (B) U373MG cells were treated with CK (50 and $75 \mu \mathrm{M})$ for $24 \mathrm{~h}$ and the expression levels of cleaved PARP, cleaved caspase-3, cleaved caspase-9, phospho-PI3K, PI3K, phospho-Akt, Akt, phospho-mTOR and mTOR were detected by western blotting. The levels of $\beta$-actin were used as an internal control.

product. As shown in Fig. 6, CK dose-dependently elevated the production of ROS in U87MG and U373MG cells in comparison with control cells.

Mitochondrial dysfunction is an early occurring event during apoptosis and includes a change in the MMP (28). Therefore, changes in the MMP of U87MG and U373MG cells after $\mathrm{CK}$ treatment was investigated using JC-1. As shown in Fig. 7, the control cells exhibited a low level of green fluorescence and a high red fluorescence (i.e., a large negative MMP), whereas treatment with CK led to an increase in green fluorescence and a decrease in red fluorescence in a dose-dependent manner (i.e., a loss of MMP). These data demonstrate that mitochondrial dysfunction may be closely related to CK-induced apoptosis of GBM cells.

Subsequently, the effect of CK on caspase activity was assessed to determine whether CK induces caspase-dependent apoptosis in GBM cells. Western blot analysis indicated that treatment with $\mathrm{CK}$ resulted in cleavage of PARP as well as activation of caspase-3 and -9 in U87MG and U373MG cells (Fig. 8). These results therefore suggest that $\mathrm{CK}$ induces apoptosis in a caspase-dependent manner in GBM cells.

Theoncogenic phosphatidylinositol3-kinase $(\mathrm{PI} 3 \mathrm{~K}) /$ protein kinase B (Akt)/mammalian target of rapamycin (mTOR) signaling axis plays a key role in the regulation of proliferation and death of various cancer cells (29). The effect of CK on the PI3K/Akt/mTOR activation was therefore investigated in GBM cells. CK significantly inhibited the phosphorylation of PI3K, Akt and mTOR in both U87MG and U373MG cells (Fig. 8), indicating that $\mathrm{CK}$ exhibits anti-proliferative and apoptotic effects in GBM cells by negatively regulating the $\mathrm{PI} 3 \mathrm{~K} / \mathrm{Akt} / \mathrm{mTOR}$ signaling axis.

Compound $K$ suppresses self-renewal capacity and invasiveness of glioblastoma stem-like cells. The stem cell subpopulation in GBM has been proposed to be a central driver
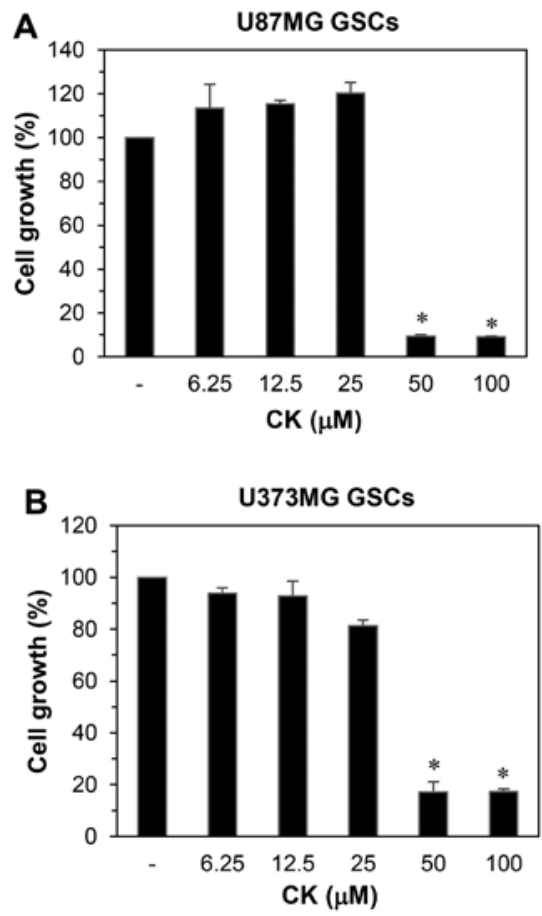

Figure 9. The growth inhibitory effect of CK on glioblastoma stem-like cells (A) U87MG and (B) U373MG GSCs were treated with increasing concentrations of $\mathrm{CK}(0,6.25,12.5,25,50$ and $100 \mu \mathrm{M})$ for 7 days and cell growth was measured by WST-1 assay. ${ }^{*} \mathrm{P}<0.05$ vs. the control.

of tumor initiation, progression, recurrence and therapeutic resistance (30). To assess the therapeutic effect of CK against cancer stem cell-like phenotypes of GBM cells, spheroid cultures for the expansion of cancer stem cell populations from U87MG and U373MG cells was examined.

The effect of CK on the growth of GSCs derived from U87MG and U373MG cells was determined using a water-soluble tetrazolium salt method. As shown in Fig. 9, CK remarkably inhibited the growth of GSCs at $50 \mu \mathrm{M}$. Furthermore, the neurosphere formation for both GSC types were markedly suppressed by treatment with $50 \mu \mathrm{M}$ CK (Fig. 10). Therefore, CK treatment demonstrated a reduction in the self-renewal capacity of GSCs, including cell growth and clonogenicity.

The invasion capabilities of GSCs also contributes to the initiation of cancer metastasis (31). As such, the anti-invasive potential of CK on GSCs from U87MG and U373MG cells was evaluated. The Matrigel invasion assay revealed that $\mathrm{CK}$ resulted in a dose-dependent reduction in the invasiveness of both GSCs (Fig. 11).

The increased expression of transcription factors, such as Sox 2, Oct4 and Nanog, has been reported to induce stem-like properties (32). Accordingly, CK treatment reduced the expression levels of the key stemness transcription factors, as well as CD133, a cell surface marker for GSCs, suggesting that the inhibitory effect of CK against GSCs may be associated with the downregulation of stemness regulators in GBM (Fig. 12).

\section{Discussion}

CK is an active ginsenoside metabolite that has been used worldwide for preventative and therapeutic purposes $(33,34)$. 
A

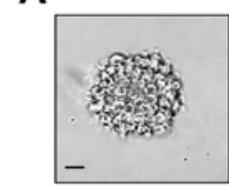

CK $(\mu \mathrm{M})$ -

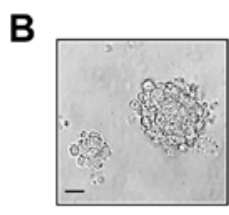

CK $(\mu \mathrm{M})$

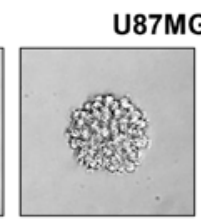

10

U373MG GSCs

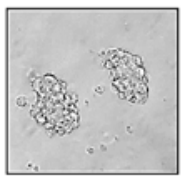

10

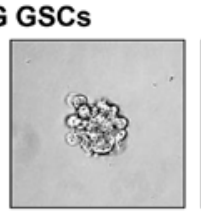

25

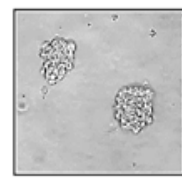

25

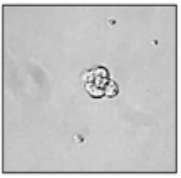

50

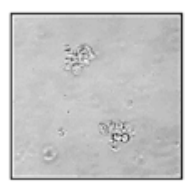

50
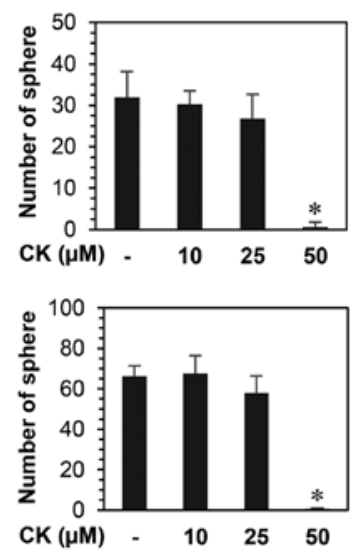

Figure 10. The effect of CK on the neurosphere-forming ability of glioblastoma stem-like cells. GSCs derived from (A) U87MG and (B) U373MG were treated with different concentration of CK $(10,25$ and $50 \mu \mathrm{M})$ for 9-12 days. The number of formed neurospheres in each well was counted under a microscope. Scale bar, $100 \mu \mathrm{m} .{ }^{*} \mathrm{P}<0.05$ vs. the control.

A

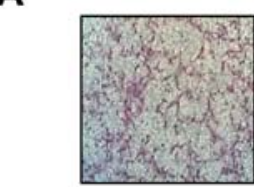

CK $(\mu \mathrm{M})$

B

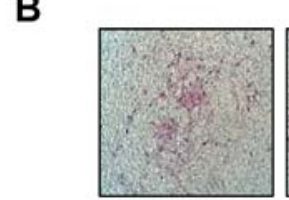

CK $(\mu \mathrm{M})$
U87MG GSCs

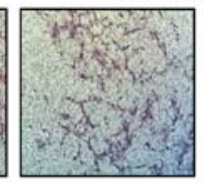

10

U373MG GSCs

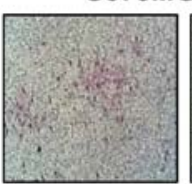

10

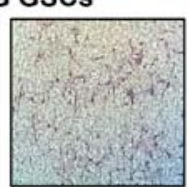

25

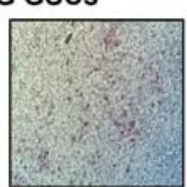

25

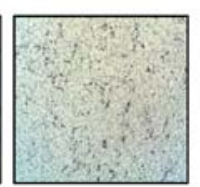

50

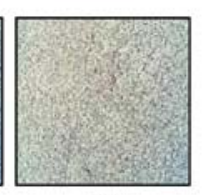

50
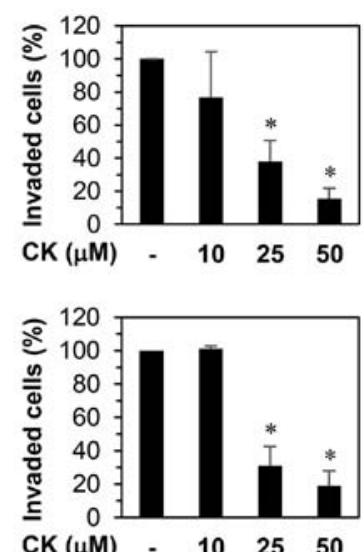

Figure 11. The effect of CK on the invasion ability of glioblastoma stem-like cells. The invasiveness of (A) U87MG and (B) U373MG GSCs was analyzed using Matrigel-coated polycarbonate filters. The GSCs were incubated in the absence or presence of CK (10, 25 and $50 \mu \mathrm{M})$ for $48 \mathrm{~h}$. The cells penetrating the filters were stained and counted under an optical microscope. ${ }^{*} \mathrm{P}<0.05$ vs. the control.
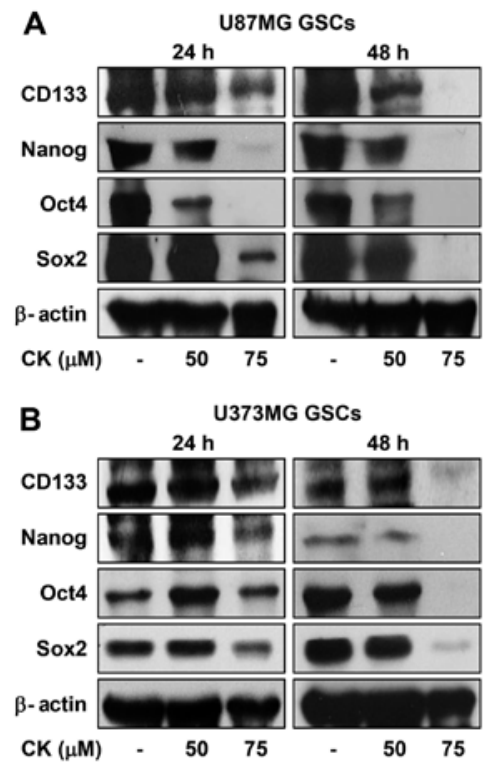

Figure 12. The effect of CK on stemness markers in glioblastoma stem-like cells. (A) U87MG and (B) U373MG GSCs were treated with CK (50 and $75 \mu \mathrm{M}$ ) for 24 and $48 \mathrm{~h}$, and the protein levels were detected by western blot analysis using specific antibodies. The levels of $\beta$-actin were used as an internal control.
A number of studies have shown that CK possesses anticancer activity against a variety of cancer cells in vitro and in vivo through the inhibition of oncogenic signaling pathways (35). However, the anticancer effects and underlying mechanisms of CK in GBM is not fully understood.

The present study assessed the chemotherapeutic ability of CK against GBM. Our results demonstrated that CK significantly inhibits the growth, metastatic potential, and stemness of GBM cells (Fig. 13). As detected by MTT and colony forming assays, CK suppressed the growth of U87MG and U373MG cells. The antiproliferative effect of CK on GBM cells was caused by arresting cell cycle progression at the G0/G1 phase and inducing apoptotic cell death. CK treatment resulted not only in the downregulation of cyclin D1 and cyclin D3 expression, but also the activation of caspase- 3 , caspase- 9 and PARP in both GBM cell types. In addition, CK suppressed the phosphorylation of PI3K, Akt and mTOR, suggesting that CK might promote G0/G1 cell cycle arrest and caspase-dependent apoptosis through the blockade of PI3K/Akt/mTOR-mediated pathways in human GBM cells.

Tumor metastasis is promoted by the increased activity of proteolytic enzymes that are involved in the destruction of the ECM (36). Proteolytic enzymes, including MMPs, have 


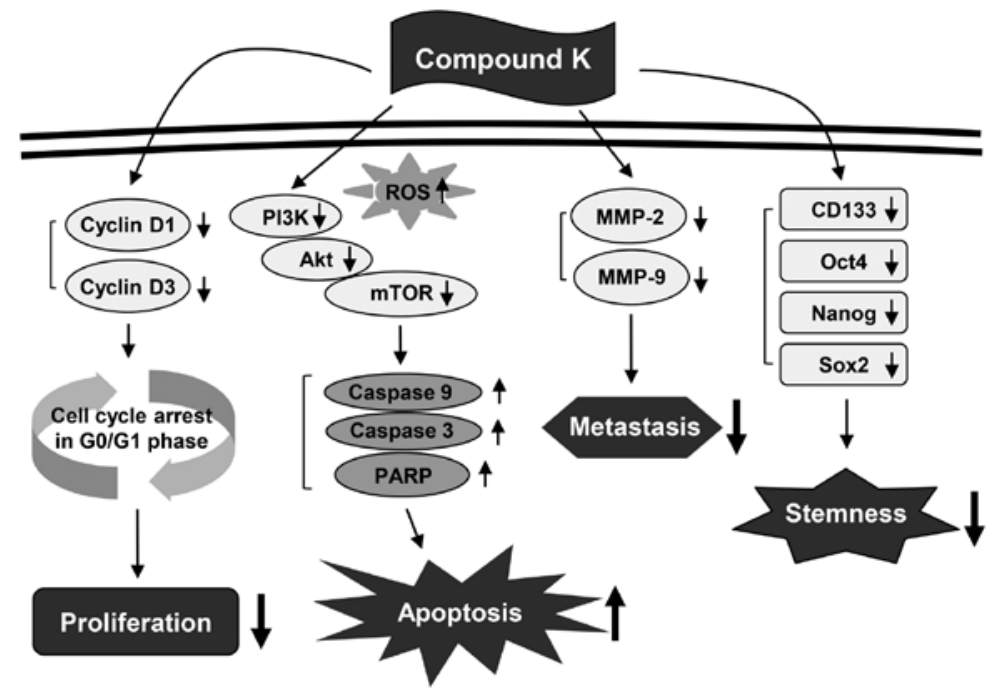

Figure 13. Proposed molecular mechanisms of anticancer action of compound $\mathrm{K}$ in human glioblastoma cells.

been overexpressed during tumor progression (37). Notably, elevated levels of MMP-2 and MMP-9 have been closely associated with the migration and invasion of human GBM cells (38). In the present study, $\mathrm{CK}$ also inhibited the migration and invasion of U87MG and U373MG cells by downregulating the expression of MMP-2 and MMP-9. Taken together, these findings indicate that $\mathrm{CK}$ possesses promising anticancer activity against GBM cells via the suppression of cell growth and metastasis.

Traditional therapies for cancer, such as surgical resection, chemotherapy and radiotherapy, have several limitations that lead to cancer recurrence (39). Causes of cancer relapse include incomplete resection, a high proliferative ability and resistance to chemotherapy and radiotherapy (40). In recent studies, cancer stem cells (CSCs) have been proposed as central drivers of tumor initiation, progression, recurrence and therapeutic resistance (41). CSCs, a subpopulation of tumor cells, have the ability to increase in number through self-regeneration and differentiate into various cell types (42). Increasing evidence has revealed that GBM also contains CSCs that contribute to tumor progression and treatment resistance (43). Therefore, targeting GSCs will improve outcomes for patients with GBM. In the present study, we determined the inhibitory effect of $\mathrm{CK}$ against the cancer stem cell-like phenotypes of U87MG and U373MG cells that were propagated through spheroid culture in serum-free media (44). CK treatment significantly reduced both the self-renewal capacity, including cell growth and clonogenicity, and the invasive potential of GSCs derived from U87MG and U373MG cells. Furthermore, CK inhibited the expression of key stemness markers for GSCs, such as CD133, Nanog, Oct4 and Sox2, which contribute to self-renewal, multilineage capabilities and heterogeneity in GSCs (45). Therefore, these results suggest that $\mathrm{CK}$ has the potential to eradicate GSCs via downregulation of cell surface glycoproteins and stemness regulatory transcription factors in GSCs.

In conclusion, the present study provides novel insights into the molecular mechanisms involved in the anticancer effect of CK in GBM for both cancer cells and cancer stem-like cells. The blood-brain barrier (BBB) excludes many therapeutic compounds and thus makes GBM treatment more difficult. Therefore, the ability of the drug to pass through the BBB is very important for efficient treatment of GBM. Although the capability of $\mathrm{CK}$ to cross the $\mathrm{BBB}$ is unclear, it has been reported to have neuroprotective and cognition enhancing effects (46). In addition, highly lipophilic ginsenoside Rd can diffuse across the BBB in an energy deficient environment (47). In light of the above, CK, as a metabolite of Rd, may cross the BBB. Together, our findings suggest that $\mathrm{CK}$ could potentially be useful in GBM treatment.

However, the precise mechanisms regarding how $\mathrm{CK}$ regulates multiple signaling pathways remain unclear. Several studies have demonstrated that CK inhibits colorectal cancer cell growth and induces apoptosis by downregulating histone deacetylase (HDAC) and DNA methyltransferase (DNMT) $(17,48)$. CK also reduces proliferation and increases apoptosis through the inhibition of epidermal growth factor receptor (EGFR) and fibroblast growth factor receptor (FGFR) activation in colon cancer and myeloma cells respectively $(49,50)$. Therefore, $\mathrm{CK}$ may regulate multiple downstream signaling pathways that are important for proliferation, apoptosis, metastasis, and stemness in GBM by targeting growth factor receptors, such as EGFR, insulin-like growth factor receptor (IGFR), FGFR, platelet-derived growth factor receptor (PDGFR) and hepatocyte growth factor receptor (c-Met), as well as key enzymes mediating the epigenetic regulation of gene expression, such as HDAC and DNMT. Further studies to identify the upstream cellular target proteins for CK will be needed to understand the exact mechanisms controlling the anticancer activity of CK against GBM.

\section{Acknowledgements}

The present study was carried out with the support of 'Cooperative Research Program for Agriculture Science and Technology Development (Project No. PJ01188001)' Rural Development Administration, Republic of Korea, the Basic Science Research Program through the National Research Foundation of Korea (NRF) funded by the Ministry of 
Education (NRF-2016R1D1A1B03932956), and the Brain Korea 21 Plus Project, Republic of Korea. The authors thank Ilhwa Co., Ltd., (Guri, Republic of Korea) for providing compound $\mathrm{K}$.

\section{References}

1. Pazhouhi M, Sariri R, Rabzia A and Khazaei M: Thymoquinone synergistically potentiates temozolomide cytotoxicity through the inhibition of autophagy in U87MG cell line. Iran J Basic Med Sci 19: 890-898, 2016.

2. Bak DH, Kang SH, Choi DR, Gil MN, Yu KS, Jeong JH, Lee NS, Lee JH, Jeong YG, Kim DK, et al: Autophagy enhancement contributes to the synergistic effect of vitamin D in temozolomide-based glioblastoma chemotherapy. Exp Ther Med 11: 2153-2162, 2016.

3. Safari M and Khoshnevisan A: Cancer stem cells and chemoresistance in glioblastoma multiform: A review article. J Stem Cells 10: 271-285, 2015.

4. Stupp R, Mason WP, van den Bent MJ, Weller M, Fisher B, Taphoorn MJ, Belanger K, Brandes AA, Marosi C, Bogdahn U, et al; European Organisation for Research and Treatment of Cancer Brain Tumor and Radiotherapy Groups; National Cancer Institute of Canada Clinical Trials Group: Radiotherapy plus concomitant and adjuvant temozolomide for glioblastoma N Engl J Med 352: 987-996, 2005.

5. Park D and Yoon M: Compound K, a novel ginsenoside metabolite, inhibits adipocyte differentiation in 3T3-L1 cells: Involvement of angiogenesis and MMPs. Biochem Biophys Res Commun 422: 263-267, 2012.

6. Attele AS, Wu JA and Yuan CS: Ginseng pharmacology: Multiple constituents and multiple actions. Biochem Pharmacol 58: $1685-1693,1999$.

7. Cho CW, Kim YC, Kang JH, Rhee YK, Choi SY, Kim KT, Lee YC and Hong HD: Characteristic study on the chemical components of Korean curved ginseng products. J Ginseng Res 37: 349-354, 2013.

8. Guo J, Chang L, Zhang X, Pei S, Yu M and Gao J: Ginsenoside compound $\mathrm{K}$ promotes $\beta$-amyloid peptide clearance in primary astrocytes via autophagy enhancement. Exp Ther Med 8: 1271-1274, 2014.

9. Qi LW, Wang CZ, Du GJ, Zhang ZY, Calway T and Yuan CS: Metabolism of ginseng and its interactions with drugs. Curr Drug Metab 12: 818-822, 2011

10. Li W, Zhang M, Gu J, Meng ZJ, Zhao LC, Zheng YN, Chen L and Yang GL: Hypoglycemic effect of protopanaxadiol-type ginsenosides and compound $\mathrm{K}$ on Type 2 diabetes mice induced by high-fat diet combining with streptozotocin via suppression of hepatic gluconeogenesis. Fitoterapia 83: 192-198, 2012.

11. Kim DY, Yuan HD, Chung IK and Chung SH: Compound K, intestinal metabolite of ginsenoside, attenuates hepatic lipid accumulation via AMPK activation in human hepatoma cells. J Agric Food Chem 57: 1532-1537, 2009.

12. Kim K, Park M, Lee YM, Rhyu MR and Kim HY: Ginsenoside metabolite compound $\mathrm{K}$ stimulates glucagon-like peptide-1 secretion in NCI-H716 cells via bile acid receptor activation. Arch Pharm Res 37: 1193-1200, 2014.

13. Akao T, Kanaoka M and Kobashi K: Appearance of compound K, a major metabolite of ginsenoside Rb1 by intestinal bacteria, in rat plasma after oral administration - measurement of compound $\mathrm{K}$ by enzyme immunoassay. Biol Pharm Bull 21: 245-249, 1998.

14. Shin KO, Seo CH, Cho HH, Oh S, Hong SP, Yoo HS, Hong JT, Oh KW and Lee YM: Ginsenoside compound K inhibits angiogenesis via regulation of sphingosine kinase-1 in human umbilical vein endothelial cells. Arch Pharm Res 37: 1183-1192, 2014.

15. Hasegawa H, Sung JH and Huh JH: Ginseng intestinal bacterial metabolite IH901 as a new anti-metastatic agent. Arch Pharm Res 20: 539-544, 1997.

16. Zhang $\mathrm{K}$ and Li Y: Effects of ginsenoside compound $\mathrm{K}$ combined with cisplatin on the proliferation, apoptosis and epithelial mesenchymal transition in MCF-7 cells of human breast cancer. Pharm Biol 54: 561-568, 2016.

17. Kang KA, Piao MJ, Kim KC, Zheng J, Yao CW, Cha JW, Kim HS, Kim DH, Bae SC and Hyun JW: Compound K, a metabolite of ginseng saponin, inhibits colorectal cancer cell growth and induces apoptosis through inhibition of histone deacetylase activity. Int J Oncol 43: 1907-1914, 2013.
18. Zhang Z, Du GJ, Wang CZ, Wen XD, Calway T, Li Z, He TC, Du W, Bissonnette M, Musch MW, et al: Compound K, a ginsenoside metabolite, inhibits colon cancer growth via multiple pathways including p53-p21 interactions. Int J Mol Sci 14: 2980-2995, 2013

19. Zheng ZZ, Ming YL, Chen LH, Zheng GH, Liu SS and Chen QX: Compound K-induced apoptosis of human hepatocellular carcinoma MHCC97-H cells in vitro. Oncol Rep 32: 325-331, 2014.

20. Aroui S, Aouey B, Chtourou Y, Meunier AC, Fetoui H and Kenani A: Naringin suppresses cell metastasis and the expression of matrix metalloproteinases (MMP-2 and MMP-9) via the inhibition of ERK-P38-JNK signaling pathway in human glioblastoma. Chem Biol Interact 244: 195-203, 2016.

21. Zou M, Zhang X and Xu C: IL6-induced metastasis modulators p-STAT3, MMP-2 and MMP-9 are targets of 3,3'-diindolylmethane in ovarian cancer cells. Cell Oncol (Dordr) 39: 47-57, 2016.

22. Yang N, Hui L, Wang Y, Yang H and Jiang X: SOX2 promotes the migration and invasion of laryngeal cancer cells by induction of MMP-2 via the PI3K/Akt/mTOR pathway. Oncol Rep 31: 2651-2659, 2014.

23. Chen BB, Glasser JR, Coon TA and Mallampalli RK: F-box protein FBXL2 exerts human lung tumor suppressor-like activity by ubiquitin-mediated degradation of cyclin D3 resulting in cell cycle arrest. Oncogene 31: 2566-2579, 2012.

24. Lin JT, Li HY, Chang NS, Lin CH, Chen YC and Lu PJ: WWOX suppresses prostate cancer cell progression through cyclin D1-mediated cell cycle arrest in the G1 phase. Cell Cycle 14: 408-416, 2015.

25. Qian C, Wang JQ, Song CL, Wang LL, Ji LN and Chao H: The induction of mitochondria-mediated apoptosis in cancer cells by ruthenium(II) asymmetric complexes. Metallomics 5: 844-854, 2013.

26. Chou YC, Chang MY, Wang MJ, Harnod T, Hung CH, Lee HT, Shen CC and Chung JG: PEITC induces apoptosis of Human Brain Glioblastoma GBM8401 Cells through the extrinsic- and intrinsic signaling pathways. Neurochem Int 81: 32-40, 2015.

27. Ray T, Chakrabarti MK and Pal A: Hemagglutinin protease secreted by $V$. cholerae induced apoptosis in breast cancer cells by ROS mediated intrinsic pathway and regresses tumor growth in mice model. Apoptosis 21: 143-154, 2016.

28. Liu Y, Jiao R, Ma ZG, Liu W, Wu QQ, Yang Z, Li FF, Yuan Y, Bian ZY and Tang QZ: Sanguinarine inhibits angiotensin II-induced apoptosis in $\mathrm{H} 9 \mathrm{c} 2$ cardiac cells via restoring reactive oxygen species-mediated decreases in the mitochondrial membrane potential. Mol Med Rep 12: 3400-3408, 2015.

29. Yu XS, Du J, Fan YJ, Liu FJ, Cao LL, Liang N, Xu DG and Zhang JD: Activation of endoplasmic reticulum stress promotes autophagy and apoptosis and reverses chemoresistance of human small cell lung cancer cells by inhibiting the PI3K/AKT/mTOR signaling pathway. Oncotarget 7: 76827-76839, 2016.

30. Bischof J, Westhoff MA, Wagner JE, Halatsch ME, Trentmann S, Knippschild U, Wirtz CR and Burster T: Cancer stem cells: The potential role of autophagy, proteolysis, and cathepsins in glioblastoma stem cells. Tumour Biol 39: 1010428317692227, 2017.

31. Jung EH, Lee HN, Han GY, Kim MJ and Kim CW: Targeting ROR1 inhibits the self-renewal and invasive ability of glioblastoma stem cells. Cell Biochem Funct 34: 149-157, 2016.

32. Guo Y, Liu S, Wang P, Zhao S, Wang F, Bing L, Zhang Y, Ling EA, Gao J and Hao A: Expression profile of embryonic stem cell-associated genes Oct4, Sox 2 and Nanog in human gliomas. Histopathology 59: 763-775, 2011.

33. Kim H, Roh HS, Kim JE, Park SD, Park WH and Moon JY: Compound $\mathrm{K}$ attenuates stromal cell-derived growth factor 1 (SDF-1)-induced migration of C6 glioma cells. Nutr Res Pract 10: 259-264, 2016.

34. Choi K, Kim M, Ryu J and Choi C: Ginsenosides compound K and $\mathrm{Rh}_{2}$ inhibit tumor necrosis factor-alpha-induced activation of the NF-kappaB and JNK pathways in human astroglial cells. Neurosci Lett 421: 37-41, 2007.

35. Yang XD, Yang YY, Ouyang DS and Yang GP: A review of biotransformation and pharmacology of ginsenoside compound K. Fitoterapia 100: 208-220, 2015.

36. Gutschalk CM, Yanamandra AK, Linde N, Meides A, Depner S and Mueller MM: GM-CSF enhances tumor invasion by elevated MMP-2, -9, and -26 expression. Cancer Med 2: 117-129, 2013

37. Kalhori V and Törnquist K: MMP2 and MMP9 participate in S1P-induced invasion of follicular ML-1 thyroid cancer cells. Mol Cell Endocrinol 404: 113-122, 2015. 
38. Chou YC, Chang MY, Wang MJ, Yu FS, Liu HC, Harnod T, Hung $\mathrm{CH}$, Lee HT and Chung JG: PEITC inhibits human brain glioblastoma GBM 8401 cell migration and invasion through the inhibition of UPA, Rho A, and Ras with inhibition of MMP-2, -7 and -9 gene expression. Oncol Rep 34: 2489-2496, 2015.

39. Lathia JD, Mack SC, Mulkearns-Hubert EE, Valentim CL and Rich JN: Cancer stem cells in glioblastoma. Genes Dev 29: 1203-1217, 2015

40. Cho DY, Lin SZ, Yang WK, Lee HC, Hsu DM, Lin HL, Chen CC, Liu CL, Lee WY and Ho LH: Targeting cancer stem cells for treatment of glioblastoma multiforme. Cell Transplant 22: 731-739, 2013.

41. Cruceru ML, Neagu M, Demoulin JB and Constantinescu SN: Therapy targets in glioblastoma and cancer stem cells: Lessons from haematopoietic neoplasms. J Cell Mol Med 17: 1218-1235, 2013.

42. Gatti M, Pattarozzi A, Bajetto A, Würth R, Daga A, Fiaschi P, Zona G, Florio T and Barbieri F: Inhibition of CXCL12/CXCR4 autocrine/paracrine loop reduces viability of human glioblastoma stem-like cells affecting self-renewal activity. Toxicology 314: 209-220, 2013

43. Ashizawa T, Miyata H, Iizuka A, Komiyama M, Oshita C, Kume A, Nogami M, Yagoto M, Ito I, Oishi T, et al: Effect of the STAT3 inhibitor STX-0119 on the proliferation of cancer stem-like cells derived from recurrent glioblastoma. Int J Oncol 43: 219-227, 2013.
44. Kim B, Jung N, Lee S, Sohng JK and Jung HJ: Apigenin inhibits cancer stem cell-like phenotypes in human glioblastoma cells via suppression of c-Met signaling. Phytother Res 30: 1833-1840, 2016.

45. Safa AR, Saadatzadeh MR, Cohen-Gadol AA, Pollok KE and Bijangi-Vishehsaraei K: Emerging targets for glioblastoma stem cell therapy. J Biomed Res 30: 19-31, 2015.

46. Oh $\mathrm{J}$ and Kim JS: Compound $\mathrm{K}$ derived from ginseng: Neuroprotection and cognitive improvement. Food Funct 7: 4506-4515, 2016

47. Ye R, Zhang X, Kong X, Han J, Yang Q, Zhang Y, Chen Y, Li P, Liu J, Shi M, et al: Ginsenoside Rd attenuates mitochondrial dysfunction and sequential apoptosis after transient focal ischemia. Neuroscience 178: 169-180, 2011.

48. Kang KA, Kim HS, Kim DH and Hyun JW: The role of a ginseng saponin metabolite as a DNA methyltransferase inhibitor in colorectal cancer cells. Int J Oncol 43: 228-236, 2013.

49. Dougherty U, Mustafi R, Wang Y, Musch MW, Wang CZ, Konda VJ, Kulkarni A, Hart J, Dawson G, Kim KE, et al: American ginseng suppresses Western diet-promoted tumorigenesis in model of inflammation-associated colon cancer: Role of EGFR. BMC Complement Altern Med 11: 111, 2011.

50. Choi HH, Jong HS, Park JH, Choi S, Lee JW, Kim TY, Otsuki T, Namba $M$ and Bang YJ: A novel ginseng saponin metabolite induces apoptosis and down-regulates fibroblast growth factor receptor 3 in myeloma cells. Int J Oncol 23: 1087-1093, 2003. 